\title{
SERINE PROTEINASE IN ARTICULAR CARTILAGE, SUBCHONDRAL BONE MARROW AND SYNOVIAL FLUID IN HUMAN OSTEOARTHRITIS AND RHEUMATOID ARTHRITIS
}

\author{
Tomoyuki Nakagawa ${ }^{1}$, Shigeki Momohara ${ }^{1}$, Kyosuke Fujita $^{1}$, Takao Kodama ${ }^{1}$, Harumoto \\ YAMADA $^{1}$ and YUTAKA NAGAI ${ }^{2}$ \\ ${ }^{1}$ Department of Orthopedic Surgery, Keio University, School of Medicine, Shinanomachi 35, Shinjukuku, Tokyo 160, and ${ }^{2}$ Depart- \\ ment of Tissue Physiology, Medical Research Institute, Tokyo Medical and Dental University, Kandasurugadai, Chiyodaku, Tokyo \\ 101, Japan
}

\begin{abstract}
To elucidate the pathophysiological role of serine proteinase in the degeneration of joint tissue in osteoarthritis (OA) and rheumatoid arthritis (RA), proteinase activity and trypsin inhibitor activity in the articular cartilage and its underneath subchondral bone marrow as well as synovial fluid were determined. Both proteinase and inhibitor extracted from minced test tissues with $2 \mathrm{M}$ guanidine hydrochloride were fractionated by Sephadex G-75 chromatography. The proteinase thus extracted was identified to be leukocyte elastase with $M_{\mathrm{r}}$ 25,000 , based on the complete inhibition with antibody to human leukocyte elastase, and its activity in OA and RA articular cartilage were 55 times and 100 times higher than that in control femoral heads, respectively. Analysis of serine proteinase and trypsin inhibitor levels in OA articular cartilage, its underneath subchondral bone marrow and synovial fluid of the test joint cavity revealed that the serine proteinase is most likely to be derived from its underneath subchondral bone marrow, while that in RA cartilage from both synovial fluid and subchondral bone marrow.
\end{abstract}

There are various destructive diseases that affect articular cartilage, of which osteoarthritis (OA) and rheumatoid arthritis (RA) are most frequently encountered in clinical practice. $\mathrm{OA}$ is a disease exhibiting localized degeneration of articular cartilage in mainly weight-bearing joints and reactive spur formation around the synoviocartilaginous junction, while RA is a systemic inflammatory disease which is characteristic of the affected articular cartilage accompanied by pannus caused by not yet defined mechanisms. However, cartilage matrix depletion in both cases is supposed to result from the involvement of tissue degrading enzymes, although precise mechanisms to differentiate OA from $\mathrm{RA}$ remains obscure $(2,4)$. In recent years, many proteinases have been demonstrated to be responsible for the degradation of cartilage matrix; however, little is known about the source and distribution of destructive enzymes and related inhibi- tors in the joint tissues including articular cartilage, its underneath subchondral bone marrow and synovial fluid in OA and RA $(10,13,20,24,26,27$, $31,33)$.

The present study was undertaken to clarify the relative distributions of proteinases and their inhibitors in the three related tissues of the joints which were affected by OA or RA to differentiate the two diseases from each other.

\section{MATERIALS AND METHODS}

\section{Materials}

Bovine pancreatic trypsin (type II), p-nitrophenylguanidinobenzoate (NPGB), soybean trypsin inhibitor (SBTI), $\varepsilon$-aminocaproicacid, dithiothreitol, elastatinal and $N$-ethylmaleimide were purchased from Sigma Chemical (St. Louis, MO). Amicon XM-100 membrane was obtained from Grace 
Table 1 Age Distribution of Cartilage, Bone Marrow and Synovial Fluid Samples Examined

\begin{tabular}{lccccc}
\hline Group & \multicolumn{3}{c}{ Age } & Total \\
& $\geqq 49$ & $50-59$ & $60-69$ & $70 \leqq$ & number \\
\hline $\begin{array}{l}\text { Rheumatoid arthritis } \\
\quad \text { (Cartilage, bone marrow) }\end{array}$ & 2 & 3 & 1 & & 6 \\
$\begin{array}{l}\text { Rheumatoid arthritis } \\
\quad \text { (Synovial fluid) }\end{array}$ & 2 & 3 & 1 & 2 & 8 \\
$\begin{array}{l}\text { Osteoarthritis } \\
\quad \text { (Cartilage, bone marrow) }\end{array}$ & 2 & 3 & 1 & 6 \\
$\begin{array}{l}\text { Osteoarthritis } \\
\quad \text { (Synovial fluid) }\end{array}$ & 2 & 5 & 2 & 9 \\
$\begin{array}{c}\text { Control } \\
\text { (Cartilage) }\end{array}$ & 2 & 3 & 1 & 6 \\
\hline
\end{tabular}

Japan (Tokyo); Spectra/Por III tube (MW3500 cutoff) from Spectrum (Los Angeles, CA); Aquacide II from Carbiochem-Behring (La Jolla, CA); Sephadex G-75 superfine from Pharmacia Japan (Tokyo). The specific antibody to human leukocyte elastase (sheep) was purchased from Binding Site (England).

\section{Tissue Samples}

Articular cartilage and bone marrow were obtained from femoral and tibial condyles at total knee replacement surgery for OA and RA. Cartilage from femoral head at hemiarthroplasty operation for femoral neck fracture with no distinction of weight-bearing or non-weight-bearing portion was employed as control. Subchondral bone marrow in $\mathrm{OA}$ and RA were collected from the region less than $5 \mathrm{~cm}$ directly underneath the test articular cartilage. Synovial fluid was obtained by aspiration from knee joints with OA or RA and immediately diluted with 4 vol of $62.5 \mathrm{mM}$ Tris-HCl buffer, pH 7.8, containing $0.15 \mathrm{M} \mathrm{NaCl}$ and $6 \mathrm{mM}$ EDTA. The resulting fluid was centrifuged at $15,000 \mathrm{~g}$ for $30 \mathrm{~min}$ to separate soluble supernatant and pellet fractions. We unfortunately failed to collect normal synovial fluid. All the samples obtained were stored at $-80^{\circ} \mathrm{C}$ before use. The age distribution of these cases is given in Table 1.

\section{Extraction and Purification of Proteinases and Inhibitors from Articular Cartilage}

The dissected articular cartilage was washed well with distilled water to remove contaminating blood. After dicing finely, the cartilage was extract- ed with $10 \mathrm{vol}$ of $2 \mathrm{M}$ guanidine hydrochloride/ Tris- $\mathrm{HCl}$ buffer, $\mathrm{pH} 7.8$, at $4^{\circ} \mathrm{C}$ according to the method described by Yamada et al. (33). After centrifugation at $15,000 \mathrm{~g}$ for $20 \mathrm{~min}$, the supernatant was ultrafiltrated through Amicon XM-100 membrane to remove macromolecules with $M_{\mathrm{r}}$ of over 100,000 . The filtrate was concentrated using Spectra/Por III tube and Aquacide II, then fractionated on a Sephadex G-75 superfine column (1.6 $\times$ $80 \mathrm{~cm}$ ) equilibrated with $0.05 \mathrm{M}$ Tris- $\mathrm{HCl}$ buffer, pH 7.8, containing $0.15 \mathrm{M} \mathrm{NaCl}$ and $5 \mathrm{mM} \mathrm{CaCl}_{2}$ (Tris-NaCl-CaCl${ }_{2}$ ) at a flow rate of $5 \mathrm{ml} / \mathrm{h}$. The fractions were stored at $-70^{\circ} \mathrm{C}$ after measuring the absorbance at $280 \mathrm{~nm}$ to estimate the protein concentration.

\section{Extraction and Purification of Proteinase from Subchondral Bone Marrow}

After dicing and mincing, the bone marrow was immediately extracted at $4^{\circ} \mathrm{C}$ with $10 \mathrm{vol}(\mathrm{ml} / \mathrm{g})$ of $2 \mathrm{M}$ guanidine hydrochloride in Tris- $\mathrm{NaCl}-\mathrm{CaCl}_{2}$ using a magnetic stirrer. The extract was treated further as employed for cartilage extract.

\section{Extraction and Purification of Proteinase from Synovial Fluids}

The soluble fraction of synovial fluid was concentrated to one fourth in volume by using Spectra/ Por III tube and Aquacide II, and mixed with an equal volume of $4 \mathrm{M}$ urea in $50 \mathrm{mM}$ Tris- $\mathrm{HCl}$, $\mathrm{pH} 7.8$, containing $1 \mathrm{M} \mathrm{NaCl}$ and $5 \mathrm{mM}$ EDTA. Then, a quarter volume of DEAE Sephadex (A-50), anion exchanger, which was swollen with $2 \mathrm{M}$ urea in $50 \mathrm{mM}$ Tris- $\mathrm{HCl}, \mathrm{pH} 7.8$, containing 
$0.5 \mathrm{M} \mathrm{NaCl}$ and $5 \mathrm{mM}$ EDTA, was added, and the resulting mixture was allowed to stand overnight, then centrifuged at $15,000 \mathrm{~g}$ for $15 \mathrm{~min}$ to remove hyaluronic acid by the batch method. The supernatant was ultrafiltrated through an Amicon YM100 membrane, concentrated and finally dialysed against $2 \mathrm{M}$ guanidine hydrochloride in Tris- $\mathrm{NaCl}$ $\mathrm{CaCl}_{2}$. One $\mathrm{ml}$ of the resulting solution, corresponding to $50 \mathrm{ml}$ of the original synovial fluid, was applied to a Sephadex G-75 superfine column. The pellet was extracted with $10 \mathrm{vol}$ of the same buffer used for the soluble fraction and the extract was ultrafiltrated with an Amicon YM-100 membrane, then immediately fractionated on a Sephadex G-75 superfine column.

\section{Assay for Gelatinolytic Activity}

The gelatinolytic activity of effluent fractions from the Sephadex G-75 superfine column was assayed using FITC-labeled gelatin (heat-denatured polymeric guinea-pig skin collagen) as substrate according to the method described by Sunada and Nagai (29), with a slight modification. FITC-labeled gelatin $(300 \mu \mathrm{g})$ in $100 \mu 1$ of Tris-NaCl-CaCl ${ }_{2}$ was incubated with $80 \mu 1$ of sample solution at $37^{\circ} \mathrm{C}$ for an appropriate time. The reaction was stopped by adding $420 \mathrm{ml}$ of ethanol and vigorous shaking. The mixture was centrifuged at $3,000 \mathrm{~g}$ for $10 \mathrm{~min}$ to precipitate undegraded gelatin substrate. Then $200 \mu 1$ portion of the supernatant was measured for fluorescence intensity using a MTP-100F microplate reader (Corona Electric, Japan).

\section{Assay for Trypsin Inhibitor Activity}

Inhibitory activity against trypsin was measured using FITC-gelatin substrate. Trypsin solution (20 ng in $30 \mu 1$ of Tris-NaCl- $\mathrm{CaCl}_{2}$ ) was incubated with $40 \mu \mathrm{l}$ of sample solution at $23^{\circ} \mathrm{C}$ for $30 \mathrm{~min}$. Then, FITC-gelatin substrate $(300 \mu \mathrm{g}$ in $100 \mu \mathrm{l}$ of Tris- $\mathrm{NaCl}-\mathrm{CaCl}_{2}$ ) was added and incubated for an appropriate time. The reaction was stopped by adding $10 \mu 1$ of $2 \mathrm{mM}$ NPGB. The trypsin inhibitory activity was determined by ethanol fractionation as described above.

\section{Effects of Various Reagents on Gelatinolytic Activity}

NPGB, SBTI, $\varepsilon$-aminocaproic acid, dithiothreitol, $N$-ethylmaleimide, EDTA, elastatinal and a specific antibody to human leukocyte elastase were incu- bated with effluent fractions $(60 \mu \mathrm{l}$ each) with maximum gelatinolytic activities $\left(23^{\circ} \mathrm{C}\right.$ for $\left.30 \mathrm{~min}\right)$ and then their residual gelatinolytic activities were determined using FITC-labeled gelatin.

Anti-human leukocyte elastase antibody employed in this study showed no inhibitory effects on human plasmin, bovine pancreatic elastase and trypsin when assayed using FITC-gelatin as substrate.

\section{SDS-Polyacrylamide Gel Electrophoresis Followed by Zymography}

Effluent fractions from Sephadex G-75 superfine column were surveyed for gelatinolytic activity and fractions showing maximum enzyme activity were subjected to SDS-PAGE in a gel $(11 \%$, $0.2 \times 10 \times 10 \mathrm{~cm}$ ) containing $0.1 \%$ gelatin. After electrophoretic run, the gel was soaked with $2.5 \%$ Triton X-100 solution for $4 \mathrm{~h}$ at room temperature, incubated in $0.1 \mathrm{M}$ glycine-NaOH buffer, $\mathrm{pH} 8.3$, at $37^{\circ} \mathrm{C}$ for $24 \mathrm{~h}$, and stained with Amido Black 10B in methanol-acetic acid-distilled water $(3: 1: 6)$ and destained with the same solvent to monitor any gelatinolytic enzyme(s), which appears as a transparent(lysis) band in the dark gel (17).

\section{RESULTS}

Comparison of Gelatinolytic Activity in Articular Cartilage, Synovial Fluid and Subchondral Bone Marrow in $O A$ and $R A$

As shown in Fig. 1, elution profiles of protein components extractable from articular cartilage indicate that those in RA cartilage were more damaged than those in OA tissue, the molecular sizes of which were intermediate between those of control and RA. When proteolytic activity in effluent fractions of cartilage extracts was determined using gelatin as substrate, two peaks of proteinase activity with apparent $M_{\mathrm{r}}$ of $70 \mathrm{kD}$ and $25 \mathrm{kD}$ were observed. The latter enzyme peak was major in all three cases, OA, RA and control, and its levels in $\mathrm{OA}$ and RA cartilage were 55 times and 100 times higher than that in control, respectively (Fig. 2).

Since $25 \mathrm{kD}$ proteinase activity was completely inhibited by incubation with anti-human leukocyte elastase antibody and other serine proteinase inhibitors (discussed later), we further examined if this serine proteinase is derived from leukocyte infiltrated into synovial fluid or from subchondral bone marrow located directly underneath the test cartilage. Fig. 3 shows that soluble (supernatant) fraction of RA synovial fluid contained a markedly 


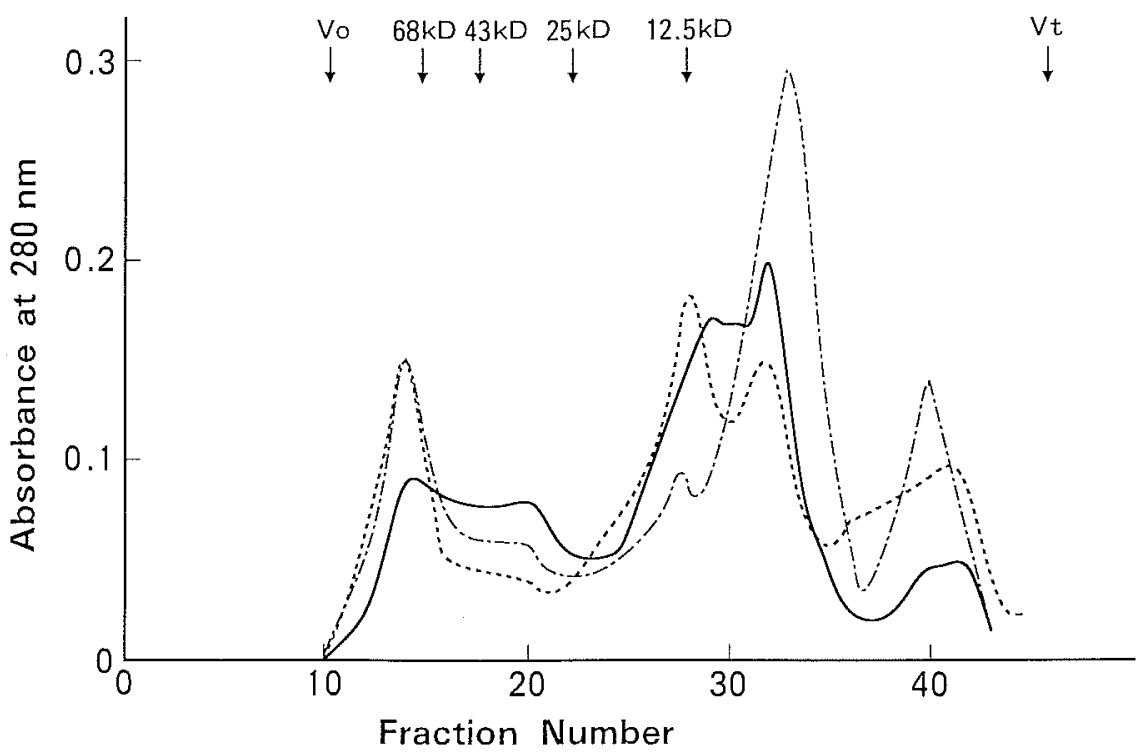

Fig. 1 Sephadex G-75 superfine chromatography of cartilage extracts. Fractions were analyzed for protein concentration at $280 \mathrm{~nm}$. Concentrated extracts $(1 \mathrm{ml})$ of $5 \mathrm{~g}$ each of RA cartilage (solid line), OA cartilage (dashed line) and control cartilage (dot-dashed line) were applied on a column $(1.6 \times 80 \mathrm{~cm})$ equilibrated with $50 \mathrm{mM}$ Tris-HCl buffer, pH 7.8, containing $0.15 \mathrm{NaCl}, 5 \mathrm{mM} \mathrm{CaCl}$ and $5 \mathrm{mM} \mathrm{NaN}_{3}(3 \mathrm{ml}$ of fractions; flow rate, $5 \mathrm{ml} / \mathrm{h}$ ). The column was calibrated using bovine serum albumin $(68 \mathrm{kD})$, egg white albumin $(43 \mathrm{kD})$, bovine pancreatic trypsinogen $(25 \mathrm{kD})$ and human cytochrome $\mathrm{C}(12 \mathrm{kD})$.

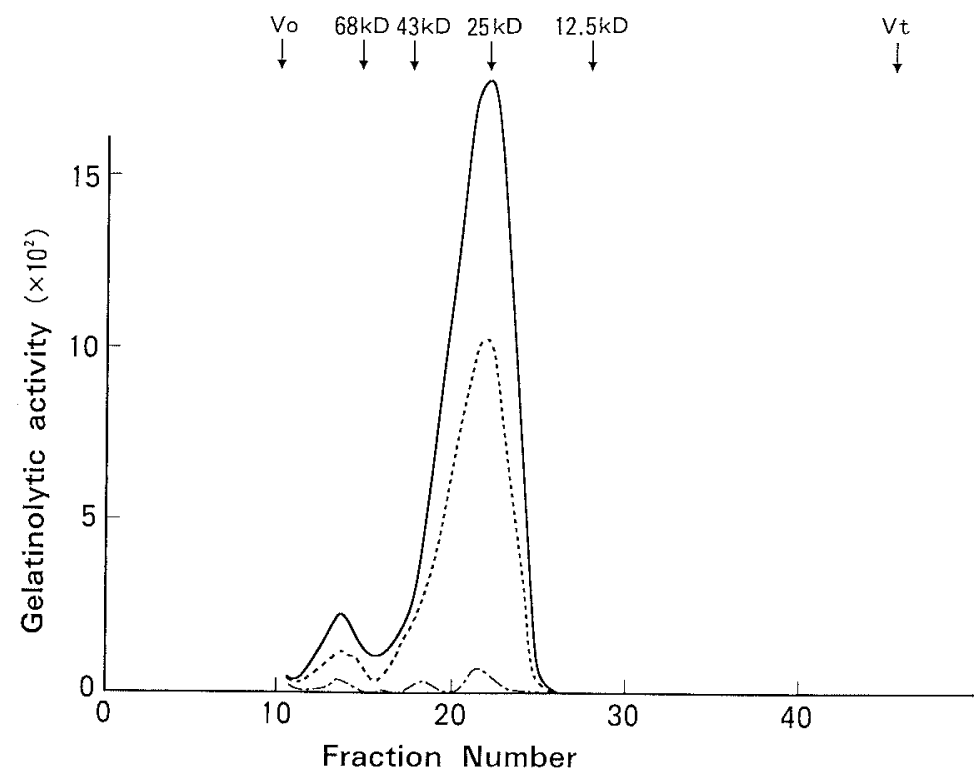

Fig. 2 Sephadex G-75 superfine chromatography of gelatinolytic enzymes of cartilage extracts. Concentrated extracts $(1 \mathrm{ml})$ of $5 \mathrm{~g}$ each of RA cartilage (solid line), OA cartilage (dashed line) and control cartilage (dot-dashed line) were applied on a column and aliquots ( $80 \mu \mathrm{l}$ each) of the effluent fractions were assayed for their gelatinolytic activity using FITC-labeled gelatin as substrate. 


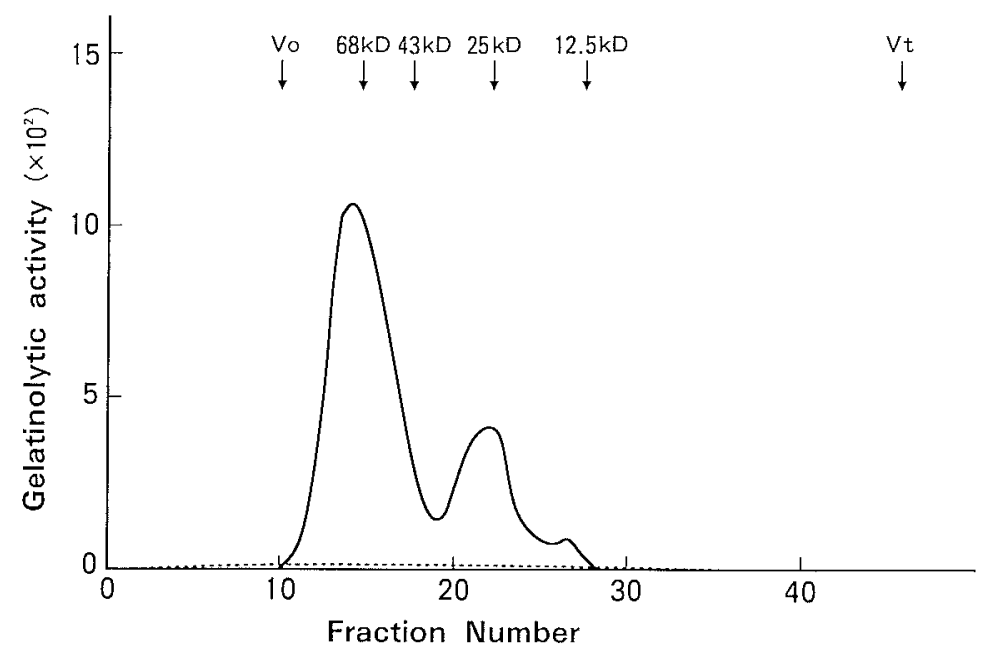

Fig. 3 Sephadex G-75 superfine chromatography of gelatinolytic enzymes of soluble fractions of synovial fluids. Concentrated extracts ( $1 \mathrm{ml}$ ) of $50 \mathrm{ml}$ each of RA synovial fluid (solid line) and OA synovial fluid (dashed line) were applied on a column and aliquots ( $80 \mu \mathrm{leach}$ ) of the effluent fractions were assayed for their gelatinolytic activity.

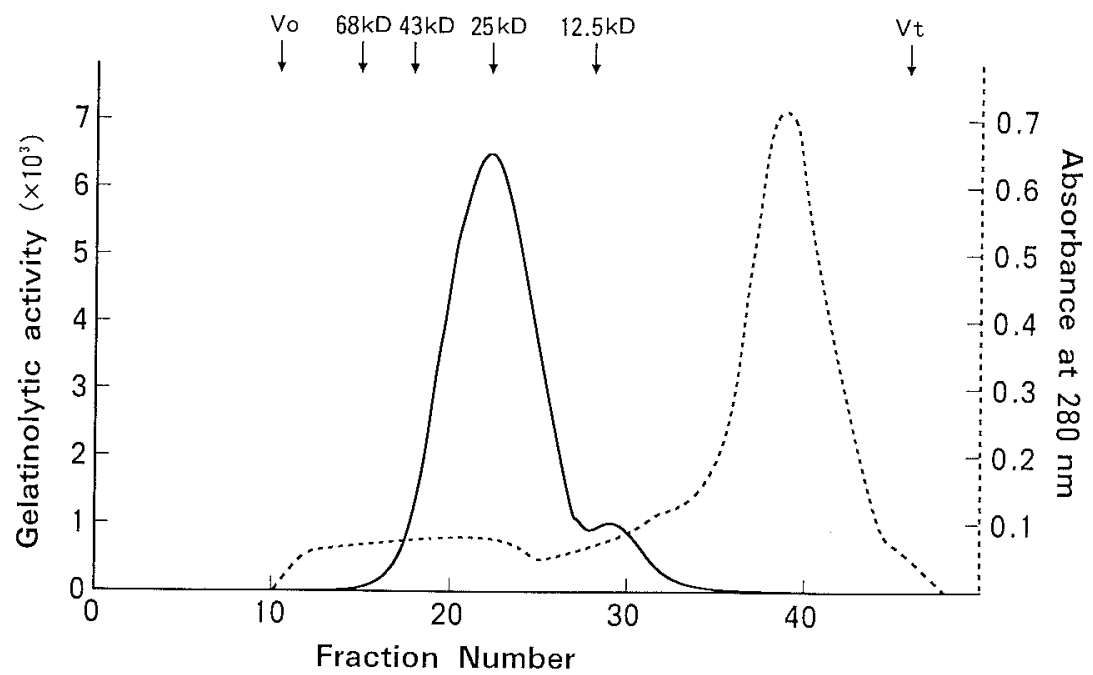

Fig. 4 Sephadex G-75 superfine chromatography of gelatinolytic enzymes of pellet fraction of RA synovial fluids. Concentrated extracts $(1 \mathrm{ml})$ of $0.1 \mathrm{~g}$ of pellet from RA synovial fluid (solid line) was applied on a column and aliquots $(80 \mu \mathrm{l}$ each) of the effluent fractions were assayed for their gelatinolytic activity.

high level of gelatinolytic activity corresponding to $70 \mathrm{kD}$ (major) and $25 \mathrm{kD}$ (minor), while no apparent proteinase activity was observed in OA synovial fluid. The pellet fraction obtained after centrifugation of RA synovial fluid is known to contain an excessive amount of infiltrated leukocytes (1). Elution profile of the pellet extract on Sephadex G-75 gel column showed a typical pattern of leukocyte elastase with $25 \mathrm{kD}$ as expected (Fig. 4). No pellet fraction was obtained from OA synovial fluid.

To our surprise, subchondral bone marrow of OA knee joint contained an elevated level of proteinase activity with $25 \mathrm{kD}$, which corresponds to leukocyte elastase, and its level was 95 times 


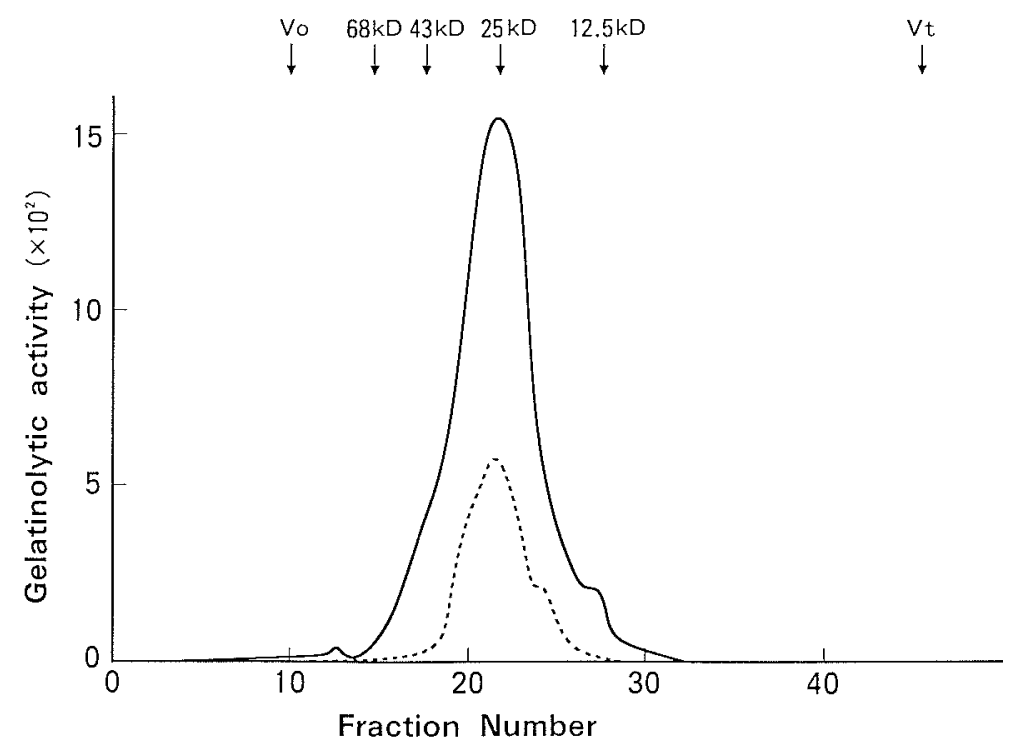

Fig. 5 Sephadex G-75 superfine chromatography of gelatinolytic enzymes of subchondral bone marrows. Concentrated extracts $(1 \mathrm{ml})$ of $5 \mathrm{~g}$ each of RA subchondral bone marrow (solid line) and OA subchondral bone marrow (dashed line) were applied on a column and aliquots $(80 \mu \mathrm{l}$ each) of the effluent fractions were assayed for their gelatinolytic activity.
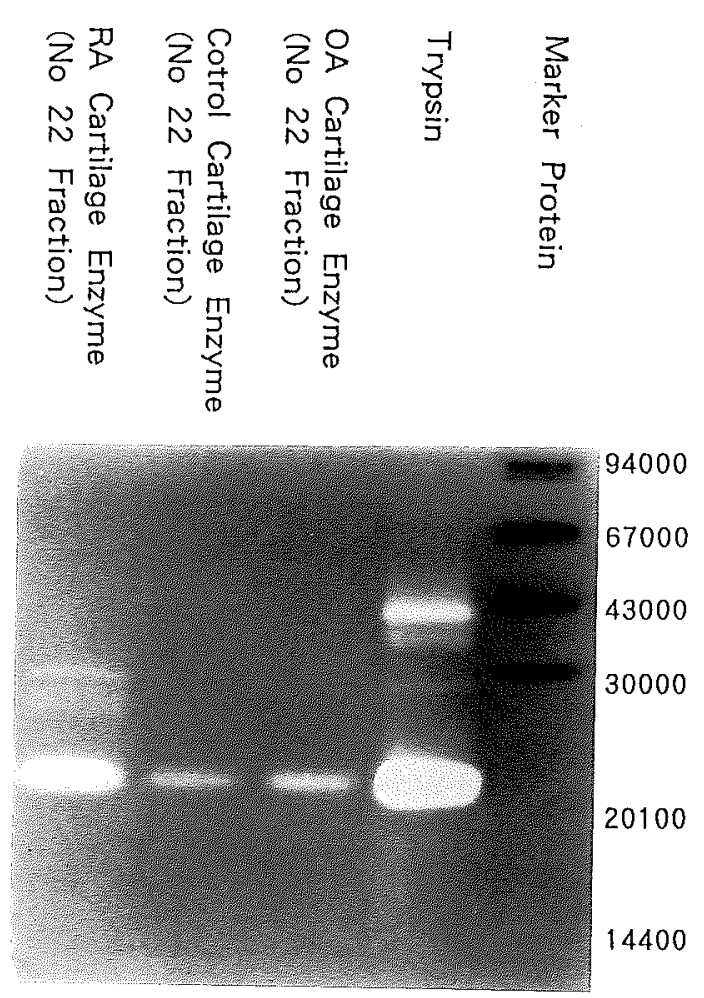

Fig. 6 Typical patterns of zymography of proteinases from OA, RA and control cartilages higher than that in control cartilage. In contrast, RA bone marrow contained the same size of proteinase about 250 times higher than that of control cartilage (Fig. 5). Fig. 6 shows the zymography of the major proteinase fraction obtained from OA and RA articular cartilage, indicating that all enzymes examined are $25 \mathrm{kD}$.

\section{Effects of Various Reagents on Gelatinolytic Enzyme Activity}

Tables 2 and 3 show the effects of various proteinase inhibitors including antibody to leukocyte elastase on $25 \mathrm{kD}$ proteinases in OA and RA cartilage, subchondral bone marrow and pellet fraction of RA synovial fluid. All the enzymes examined were completely inhibited by NPGB, SBTI and antibody to leukocyte elastase, but not by other types of inhibitors, indicating that $25 \mathrm{kD}$ enzyme in OA and RA cartilage, synovial fluid and subchondral bone marrows is serine proteinase and identical with leukocyte elastase.

Trypsin Inhibitor Activity of Cartilage Extracts Since we found that the major tissue-degrading 
Table 2 Effects of Various Reagents on Cartilage Gelatinolytic Enzymes

\begin{tabular}{lcrrr}
\hline \multicolumn{1}{c}{ Reagent } & $\begin{array}{c}\text { Concentration } \\
(\mathrm{mM})\end{array}$ & RA & OA & Control \\
\hline NPGB & 0.5 & 100 & 100 & 100 \\
SBTI & $250(\mu \mathrm{g} / \mathrm{ml})$ & 100 & 100 & 100 \\
$\varepsilon$-Amino- $n$-caproic acid & 100 & 0 & 65 & 0 \\
Dithiothreitol & 5 & 0 & 0 & 0 \\
$N$-ethylmalemide & 5 & 0 & 0 & 0 \\
Pepstatin & $4(\mu \mathrm{g} / \mathrm{ml})$ & 0 & 0 & 0 \\
EDTA & 40 & 0 & 0 & 0 \\
Elastatinal & $40(\mu \mathrm{l} / \mathrm{ml})$ & 0 & 0 & 0 \\
Anti-leukocyte elastase antibody & $1.4(\mathrm{mg} / \mathrm{ml})$ & 100 & 100 & 100 \\
\hline
\end{tabular}

Gelatinolytic enzymes from rheumatoid (RA), osteoarthritic (OA) and control cartilage ( $60 \mu 1$, fraction number 22 in Fig. 2) were preincubated with $20 \mu 1$ of each reagent for 30 min at $23^{\circ} \mathrm{C}$. Then, residual enzyme activity was assayed using FITC-labeled gelatin as substrate. NPGB, p-nitrophenyl-n-guanidinobenzoate; SBTI, soybean trypsin inhibitor; EDTA, ethylenediaminetetraacetic acid

Table 3 Effects of Various Reagents on Gelatinolytic Enzymes of Bone Marrow and Pellet

\begin{tabular}{lcccc}
\hline \multicolumn{1}{c}{ Reagent } & $\begin{array}{c}\text { Concentration } \\
(\mathrm{mM})\end{array}$ & $\begin{array}{c}\text { RA } \\
\text { bone marrow }\end{array}$ & $\begin{array}{c}\text { OAhibition }(\%) \\
\text { OA }\end{array}$ & $\begin{array}{c}\text { RA } \\
\text { pellet }\end{array}$ \\
\hline NPGB & 0.5 & 100 & 100 & 100 \\
SBTI & $250(\mu \mathrm{g} / \mathrm{ml})$ & 100 & 100 & 96 \\
$\varepsilon$-Amino- $n$-caproic acid & 100 & 10 & 0 & 0 \\
Dithiothreitol & 5 & 55 & 30 & 20 \\
$N$-ethylmalemide & 5 & 0 & 0 & 45 \\
Pepstatin & $4(\mu \mathrm{g} / \mathrm{ml})$ & 0 & 0 & 0 \\
EDTA & 40 & 15 & 0 & 0 \\
Elastatinal & $40(\mu 1 / \mathrm{ml})$ & 30 & 0 & 20 \\
Anti-leukocyte elastase antibody & $1.4(\mathrm{mg} / \mathrm{ml})$ & 100 & 100 & 100 \\
\hline
\end{tabular}

Gelatinolytic enzymes from RA subchondral bone marrow, OA subchondral bone marrow and pellet from rheumatoid synovial fluid ( $60 \mu 1$, fraction number 22 in Figs. 4 and 5) were preincubated with $20 \mu \mathrm{l}$ of each reagent for $30 \mathrm{~min}$ at $23^{\circ} \mathrm{C}$. Then, residual enzyme activity was assayed using FITC-labeled gelatin as substrate. NPGB, $p$-nitrophenyl-n-guanidinobenzoate; SBTI, soybean trypsin inhibitor; EDTA, ethylenediaminetetraacetic acid

proteinase in cartilage extract was serine enzyme and derived from leukocytes, the presence of serine proteinase inhibitor in articular cartilage was examined and compared between OA and RA. Fig. 7 shows that elution profiles of trypsin inhibitor activity in cartilage extract. A single peak of the inhibitory activity with approximately $14 \mathrm{kD}$ was observed in all cases of OA and RA as well as control, in which control cartilage contained a potent inhibitory activity compared to both diseased cartilage and the activity in OA was less than one eighth of control. Much less or little inhibitory activity was detected in RA cartilage, suggestig that the content of proteinase inhibitor seems to be inversely proportional to the severity of joint disease, which is closely related to the level of proteinase activity $(1,33)$.

\section{DISCUSSION}

In our previous reports, we demonstrated the presence of serine proteinase and its specific inhibitor in articular cartilage and meniscus $(20,33)$. The enzyme was capable of degrading not only gelatin 


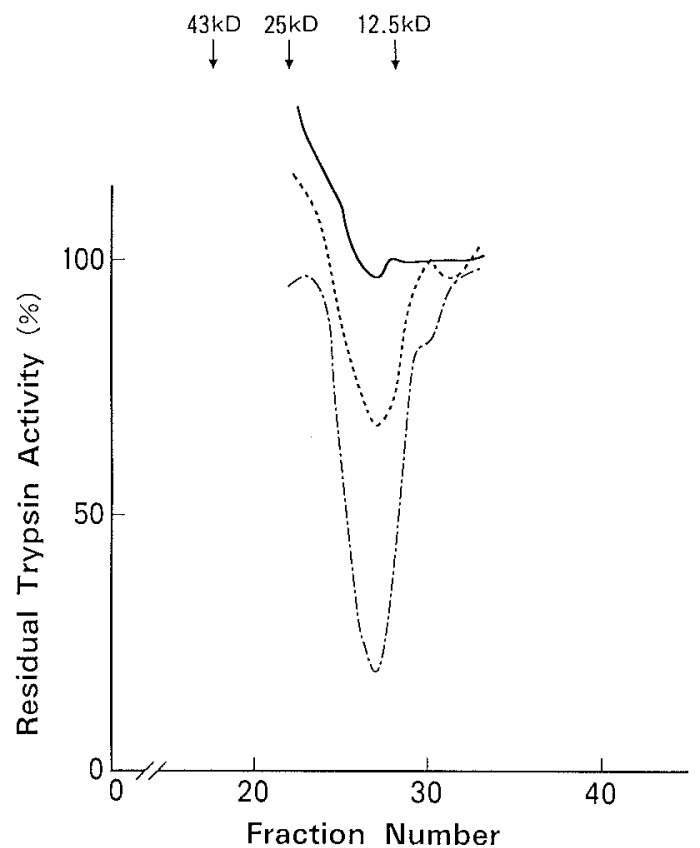

Fig. 7 Elution profiles of trypsin inhibitor activity of cartilage extracts on Sephadex G-75 superfine chromatography. Concentrated extracts $(1 \mathrm{ml})$ of $5 \mathrm{~g}$ each of RA cartilage (solid line), OA cartilage (dashed line) and control cartilage (dot-dashed line) were applied on a column and aliquots $(40 \mu 1$ each) of effluent fractions were assayed for their trypsin inhibitory activity using FITClabeled gelatin as substrate.

but also proteoglycan subunit and its aggregates, and its activity was significantly higher in degenerative tissue than in control tissue. In contrast, trypsin inhibitor level was decreased with advancement of degenerative stage. Furthermore, the presence of a serine proteinase sensitive to anti-human leukocyte elastase antibody was demonstrated in human degenerated intervertebral disc, and an elevated level of the enzyme activity was detected in the bone marrow of the vertebral body adjacent to the diseased disc. This is quite a contrast to normal disc, where no detectable gelatinolytic activity was observed. So far no evidence for the synthesis of serine proteinase in the cartilaginous tissue has been reported, except for plasminogen activator $(5$, 7). These results strongly suggests that serine elastase accumulated in the diseased disc is originated from the bone marrow probably due to an inflow of the enzyme from bone marrow of vertebral body into nucleus pulposus of the disc through the end plate (12).

The current study demonstrated that serine pro- teinases extraced from control, OA and RA articular cartilage with $2 \mathrm{M}$ guanidine hydrochloride were also leukocyte elastase. From where and how this enzyme reached to articular cartilage remains unclear. But the distribution of this enzyme in OA knee joints provides a possibility for the influx of leukocyte elastase from bone marrow to articular cartilage. The subchondral nutritional pathway is thought to function only in younger ages and that of normal articular cartilage is considered to be through synovial fluid in the adult after formation of tide mark and calcified cartilage zone which could completely separate chondrocytes from bone marrow cells (19). Therefore, serine elastase present in control cartilage would be derived from synovial fluid $(5,7)$. But the enzyme activity was not detectable in OA synovial fluid and probably neither in normal synovial fluid. Then, a question arises where the origin of leukocyte elastase extracted from control cartilage was. Recently, a trace amount of leukocyte elastase was detected in OA synovial fluid using Superose 12 (FPLC-System, Pharmacia) or ELISA $(16,21)$. Normal synovial fluid may also contain a trace amount of leukocyte elastase, which will be trapped in articular cartilage, thus taking part in metabolism of cartilage matrix under physiological condition (3). This enzyme does not seem to be distributed uniformly, but rather unevenly in the cartilage tissue because gelatinolytic activities in weight-bearing portion was higher than that in non-weight-bearing portion of apparently normal femoral head cartilage (33).

In osteoarthritic condition, even in the early stage, irregular tide mark and interruption of calcified cartilage were frequently observed and sometimes small vessels penetrated from subchondral bone marrow into cartilage were demonstrated, as described by Sokoloff (28). In such a condition, human leukocyte elastase would be easily permeable from bone marrow through calcified cartilage hole into cartilage matrix. Our observation on the elevated level of elastase activity in subchondral bone marrow in OA compared to its synovial fluid with no appreciable enzyme activity, strongly suggests that the major portion of the leukocyte elastase in OA cartilage may originate from the bone marrow.

RA bone marrow extract contained gelatinolytic activity 2.5 times as much as $\mathrm{OA}$ bone marrow extract, suggesting that major part of serine enzyme found in RA articular cartilage would also originate from its subchondral bone marrow. However, in the case of RA, the pellet of synovial fluid, that is 
cell fraction, contained a significantly high enzyme activity, although its soluble fraction did much less proteinase activity. Therefore, serine elastase in RA articular cartilage would be supplied from synovial fluid, especially polymorphonuclear neutrophils in the pellet $(1,32)$ and/or from both synovial fluid and bone marrow.

The proteinase activity in the soluble fraction of RA synovial fluid showed $M_{\mathrm{r}} 70,000$ and 25,000 on Sephadex G-75 superfine chromatography, in which $M_{\mathrm{r}} 70,000$ enzyme was major (Fig. 3). This is quite a feature distinct from cartilage, bone marrow and pellet, where $M_{\mathrm{r}} 25,000$ enzyme was major (Figs. 2, 4 and 5). A similar size $\left(M_{\mathrm{r}} 70,000\right)$ of enzyme, which was completely neutralized with anti-leukocyte elastase antibody, was observed in human vertebral disc extract, and its zymogram showed a distinct band corresponding to $M_{\mathrm{r}} 25,000$ with faint and broad bands ranging $M_{\mathrm{r}} 45,000 \sim M_{\mathrm{r}}$ 68,000 , indicating that $M_{\mathrm{r}} 70,000$ enzyme is a complex or modified form of $M_{\mathrm{r}} 25,000$ elastase (12). The $M_{\mathrm{r}} 70,000$ enzyme observed with RA synovial fluid in this study was anti-leukocyte elastase antibody sensitive. This suggests that $M_{\mathrm{r}} 70,000$ enzyme in synovial fluid may also be in a complex or modified form with other fluid constituent(s), especially with degradation products of hyaluronic acid and/or proteinase inhibitors as observed with collagenase in RA synovial fluid (1). The use of Amicon YM-100, instead of XM-100 membrane used for cartilage extract, may be an alternative reason for the complex formation, although it is not confirmed in this study.

Trypsin inhibitor which neutralized this leukocyte elastase was detected only in cartilage, but not in bone marrows and synovial fluids. Therefore, this inhibitor seems to be synthesized by chondrocytes. The depletion of serine proteinase inhibitor and accumulation of excess serine elastase in the degenerated cartilage were reported in our previous paper (33). The present study revealed that the imbalance between tissue-destructive proteinase and its specific inhibitor became more distinct in RA articular cartilage, which is known to be more degenerative than in OA.

It is of interest that neutrophils at all differentiating stages of bone marrow except for myeloblasts contain an abundant amount of leukocyte elastase $(11,18,30)$. Ochi described the existence of abnormal myelocytes in the bone marrow of RA $(22,23)$. A markedly elevated activity of elastase in RA bone marrow may originate from this abnormal myelocytes (see Fig. 5).
It remains unclear how prevention mechanisms of the barrier at the junction between cartilage and bone marrow are deteriorated. However, once preventive barriers are disturbed for not yet defined reasons such as enzymatic degradation of calcified cartilage zone, mechanical force, etc., leukocyte elastase with $M_{\mathrm{r}} 25,000$ could easily penetrate into the cartilage from bone marrow and start to degrade the cartilage matrix. Dingle demonstrated a significant destruction of cartilage matrix in vitro, when articular cartilage explants were incubated with bone marrow tissue (9). Bone marrow cells also secrete cytokines such as interleukin-1 and tumor necrosis factor, which could easily flow into cartilage, thus stimulating chondrocytes to produce matrix metalloproteinases $(6,8,14,15)$. Another pathological function of leukocyte elastase in degeneration of cartilage tissue is to reactivate inactive complexes of metalloproteinase and tissue inhibitor of metalloproteinases (TIMP) by degrading TIMP (25). In the pathology of OA and RA, the imbalance between leukocyte elastase and its specific inhibitor may result in the degradation of cartilage matrix in concert with the matrix metalloproteinase system.

Received 28 November 1994; and accepted 9 December 1994

\section{REFERENCES}

1. ABE S. and NAGAI Y. (1973) Collagenases in synovial fluids-The regulation mechanisms of the enzyme activity and its pathophysiological significance. J. Jap. Med. Assoc. 69, 933-948 (in Japanese)

2. Ali S. Y. (1973) Enzymatic degradation of cartilage in osteoarthritis. Fed. Proc. 32, 1494-1498

3. Baici A. and Bradamante P. (1984) Interaction between human leukocyte elastase and chondroitin sulphate. Chem. Biol. Interact. 51, 1-11

4. BARRett A. J. (1981) Which proteinases degrade cartilage matrix? Semin. Arthritis Rheum. 11, Suppl. 1, 52-56

5. Bunning R. A. D., Crawford A. and Richardson H. J. (1987) Interleukin 1 preferentially stimulates the production of tissue-type plasminogen activator by human articular chondrocytes. Biochim. Biophys. Acta 924, 473-482

6. Bunning R. A. D. and Russel R. G. G. (1989) The effect of tumor necrosis factor $\alpha$ and $\gamma$-interferon on the resorption of human articular cartilage and caseinase activity by human articular chondrocytes. Arthritis Rheum. 32, 780-784

7. Campbell I. K., Piccoli D. S., Butler D. M., Singleton D. K. and Hamilton J. A. (1988) Recombinant human interleukin-1 stimulates human articular cartilage to undergo resorption and human chondrocytes to produce both tissue- and urokinase-type plasminogen activator. Biochem. Biophys. Acta 967, 183-194 
8. Chang J., Gilmans S. C. and Lewis A. J. (1986) Interleukin 1 activates phospholipase $\mathrm{A}_{2}$ in rabbit chondrocytes: A possible signal for IL 1 action. J. Immunol. 136, 1283-1287

9. Dingle J. T. (1984) The role of cellular interactions in joint erosions. Clin. Orthop. 182, 24-30

10. Ehrlich M. G., Mankin H. J., Jones H., Wright R., CriSPEN C. and VigLiani G. (1977) Collagenase and collagenase inhibitors in osteoarthritic and normal cartilage. $J$. Clin. Invest. 59, 226-233

11. Fouret P., Du Bois R. M., Bernaudin J. F., Takahashi H., Ferrans V. J. and Crystal R. G. (1989) Expression of the neutrophil elastase gene during human marrow cell differentiation. J. Exp. Med. 169, 833-845

12. Fujita K., Nakagawa T., Hirabayashi K. and Nagi Y. (1993) Neutral proteinases in human intervertebral disc: role in degeneration and probable origin. Spine 18, 17661773

13. Ghosh P. (1989) The role of serine proteinases and serine proteinase inhibitors in the pathobiology of connective tissue. J. Jap. Orthop. Assoc. 63, 643-652

14. Ghosh P., Collier S. A. and Andrews J. L. (1987) Synovial membrane-cartilage interactions- - the role of serine proteinase inhibitors in interleukin-1 mediated degradation of articular cartilage. J. Rheumatol. 14, Suppl., 122-124

15. Gilman S. C. (1987) Activation of rabbit articular chondrocytes by recombinant human cytokines. J. Rheumatol. 14, 1002-1007

16. GReILING H., KLEEsieK K. and Reinards R. (1986) Interaction of synovial cells and synovial fluid with cartilage. In Articular Cartilage Biochemistry (ed. KUETTNER K. E., ScHLEYERBACH R. and Hascall V.) Raven Press, New York, pp. 195-210

17. Heussen C. and Dowdle E. B. (1980) Electrophoretic analysis of plasminogen activators in polyacrylamide gels containing sodium dodecylsulphate and polymerized substrtate. Anal. Biochem. 102, 196-202

18. Kramps J. A., Van Der Valk P., Van Der Sandt M. M., LindeMAN J. and MEIJER C. J. M. (1984) Elastase as a marker for neutrophilic myeloid cells. J. Histchem. Cytochem. 32, 389-394

19. McKibin B. and Maroudas A. (1979) Nutrition and metabolism. In Adult Articular Cartilage (ed. FrEEMAN M. A. R.) Pitman Medical, Kent, pp. 461-486

20. NaKagawa T., Ghosh P. and Nagai Y. (1983) Serine proteinase and serine proteinase inhibitors of normal and degenerate knee joint menisci. Biomedical Res. 4, 25-32

21. Neumann S., Hennrich N., Gunzer G. and Lang H.
(1984) Potential role in health and disease. In Proteinase (ed. Horl W. and Heiland A.) Plenum Press, New York, pp. 379-390

22. OCHI T. (1988) The presence of a myeloid cell production showing strong reactivity with monoclonal antibody directed to difucosyl type 2 chain in epiphyseal bone marrow adjacent to joints affected with rheumatoid arthritis and its abscence in the corresponding normal and non-RA bone marrow. J. Rhetmatol. 15, 1609-1615

23. OCHI T. (1990) Elevated activity of interleukin-1 in epiphyseal bone marrow adjacent to the affected joints in patients with rheumatoid arthritis. Arthritis Rheum. 33, Suppl., 149

24. Okada Y., Nagase H. and Harris E. D. (1987) Matrix metallproteinases 1,2 and 3 from rheumatoid synovial cells are sufficient to destroy joints. $J$. Rheumatol. 14, 41-42

25. OKada Y., WATANABE S. and NAKANISHI I. (1988) Inactivation of tissue inhibitor of metalloproteinases by neutrophil elastase and other serine proteinases. FEBS Lett. 29, 157160

26. Pelletier J. M., Pelletier J. P. and Cloutier J. M. (1984) Neutral proteinases capable of proteoglycan digesting activity in osteoarthritic and normal human articular cartilage. Arthritis Rheum. 27, 305-312

27. Pelletier J. P., Pelletier J. M. and Howell. D. S. (1983) Collagenase and collagenolytic activity in human osteoarthritic cartilage. Arthritis Rheum. 26, 63-68

28. Sokoloff L. (1969) The Biology of Degenerative Joint Disease. Univ. Chicago Press, Chicago, pp. 5-30

29. SunAdA H. and NAGAI Y. (1980) A rapid microassay method for gelatinolytic activity using tritium-labeled heat-denatured polymeric collagen as a substrate and its application to the detection of enzymes involved in collagen metabolism. J. Biochem. 87, 1765-1771

30. Takahashi H., Nukiwa T., Basset P. and Crystal R. G. (1988) Myelomonocytic cell lineage expression of the neutrophil elastase gene. J. Biol. Chem. 263, 2543-2547

31. Walton E. A., Upfold L. I., Stephens R. W., Ghosh P. and TAYLOR T. K. F. (1981) The role of serine proteinase inhibitors in normal and osteoarthritichuman articular cartilage. Semin. Arthritis Rheum. 11, Suppl. 1, 73-74

32. Watanabe H., Hattori S., Katsuda S., Nakanishi I. and NAGAI Y. (1990) Human neutrophil elastase: Degradation of basement membrane components and immunolocalization in the tissue. J. Biochem. 108, 753-759

33. Yamada H., Nakagawa T., Stephens R. W. and Nagai Y. (1987) Proteinases and their inhibitors in normal and osteoarthritic articular cartilage. Biochem. Res. 8, 289-300 